\title{
DESCRIPTIO Y PASIONES EN LA TEORÍA DE LA PERSUASIÓN DE LUIS DE GRANADA
}

\author{
Francisco Burdiles \\ Universidad Alberto Hurtado \\ Santiago, Chile \\ fburdiles@gmail.com
}

\section{RESUMEN / ABSTRACT}

Este artículo estudia la descriptio y las pasiones en la teoría de la persuasión de Luis de Granada en el Libro de la oración y meditación (1554) y la Retórica eclesiástica (1576). Para ello, indaga en algunas preceptivas retóricas, tanto antiguas como renacentistas, con el propósito de delinear la trayectoria de este recurso e identificar similitudes y diferencias con la propuesta granatense. A su vez, para comprender la importancia que el autor le asigna a la descriptio, analiza el lugar de la imagen y la visión en la religiosidad católica durante el siglo XVI. Finalmente, reflexiona sobre la relación entre palabra e imagen en la España del Siglo de Oro, planteando su reformulación a partir de la distinción entre narración y descripción.

Palabras clave: Luis de Granada, descriptio, retórica, cultura visual, Siglo de Oro.

\section{ECPHRASIS AND PASSIONS IN LUIS DE GRANADA'S THEORY OF PERSUASION}

This article studies the descriptio and the passions in Luis de Granada's theory of persuasion present in his Libro de la oración y meditación (1554) and Retórica eclesiástica (1576). For this purpose, the study inquires into some rhetoric precepts belonging to both the Ancient World and the Reinassance, in order to outline the trajectory of this resource and identify the similarities and differences as compared to the author's proposal. Furthermore, we analyze the place of the image and vision within Catholic religiosity in the XVI century to understand the importance of the descriptio technique given by Granada's thinking. Finally, this article reflects upon the relationship between word and image in the Spanish Golden Age, suggesting a reformulation that comes from the distinction between narration and description.

KEYWords: Luis de Granada, descriptio, rhetoric, visual culture, Golden Age.

Recepción: 30/12/2019

Aprobación: 02/03/2020 
Las polémicas que se generaron en el seno de la Iglesia Católica durante los siglos XIV, XV y XVI, cuyo punto de inflexión fueron los procesos de la Reforma y la contrarreforma, favorecieron el florecimiento de la escritura religiosa, ya sea como parte de las polémicas teológicas o en la implementación de un plan de control de la vida piadosa de los fieles a través de la literatura espiritual. Este auge no solo se entiende a partir del aumento del volumen de obras (lo que se podría explicar por otros factores, como el desarrollo de la imprenta), sino que también por la diversificación de los formatos discursivos y las ideas religiosas, doctrinales o devocionales, a pesar del control de la Inquisición. El contexto español fue particularmente profuso en este sentido, como lo indica Jean Delumeau al hablar de un renacimiento de la teología española (47-48) y Carlos González Sánchez al estudiar la literatura espiritual contrarreformista ("Lection espiritual" 274). Uno de los principales representantes de este contexto fue el dominico Luis de Granada, quien alcanzó una fama notable en los territorios de la monarquía española y portuguesa ${ }^{1}$.

Este artículo estudia la descriptio dentro de la teoría de la persuasión de Luis de Granada a partir del Libro de la oración y meditación $(1554)^{2}$ y de la Retórica eclesiástica $(1576)^{3}$. Para realizar este propósito se adopta una perspectiva teórico-metodológica que se inscribe en un cruce interdisciplinario entre los estudios retóricos y la historia cultural. Esto implica relacionar los textos de estudio y su teoría sobre la persuasión con aquellos contextos y procesos históricos que son su condición de posibilidad, al mismo tiempo que su espacio de acción. De allí que la opción metodológica sea mirar el contexto cultural de la España del siglo XVI por intermedio de las obras de Granada, ya que, como se sostiene en este artículo, tiene un valor representativo de algunas de sus principales transformaciones y características.

Para profundizar en la popularidad de las obras de Luis de Granada en Europa revisar las obras de Marcel Bataillon (588) y Lucien Febvre y Henri-Jean Martin (296-330). Con respecto a su difusión en América, Irving Leonard y Carlos González destacan su enorme presencia en los embarques de libros que se enviaban desde la metrópolis por encargo de los comerciantes libreros (Leonard 289, 355, 372; González Sánchez, Los mundos 77, 85-86).

El nombre completo es Libro de la Oración y Meditación en el qual se trata de la consideración de los principales mysterios de nuestra $F e$, con otras cosas provechosas. $Y$ de las partes y doctrina para la oración.

El nombre completo en latín es Ecclesiastica Rhetorica sive De ratione concionandi libri VI. En esta investigación se trabajó con la edición y traducción de Manuel López-Muñoz. 
Aunque las investigaciones sobre Luis de Granada no son abundantes, tampoco nos encontramos en un terreno baldío. Es posible reconocer dos momentos particularmente relevantes en la historia de los estudios sobre su vida y obra. Primero, el Congreso Internacional: Fray Luis de Granada. Su obra y su tiempo, realizado en 1988, y cuyas actas fueron editadas en dos volúmenes por la Universidad de Granada en 1993. Y en segundo lugar, la traducción y edición moderna de su Retórica eclesiástica, a cargo de Manuel López-Muñoz, quien revitalizó los estudios sobre el dominico a partir de su teoría retórica. Entre los estudios producidos en estos treinta años, encontramos investigaciones de sus aspectos biográficos (Alonso del Campo, Vida y obra); su escritura espiritual y ejercicios ascéticos (Rico, "Una batalla"; Huerga, Fray Luis); su influencia en la escritura de Teresa de Ávila (Borriello); su teoría retórica y sermones (Herrero; López-Muñoz); las características literarias (elocutivas) de su escritura (López Fe; Sánchez Mesa; Turrado). Son particularmente importantes para esta investigación los trabajos de Sánchez Mesa y Darío Velandia (Hacia una teología 169-190), ya que proponen mirar la obra devocional de Granada en relación con la producción pictórica de fines del siglo XVI y del XVII, encontrando similitudes en el tratamiento de algunos temas devocionales. En ambos se da cuenta de la descriptio en la escritura ascética del granatense, pero no se profundiza en sus aspectos retóricos, ni los vínculos de estos con la literatura espiritual y el escenario religioso.

Por otro lado, sobre la importancia de las imágenes y lo visual en los reinos españoles de la Época Moderna se han realizado aportes desde distintos campos de estudio, como las relaciones interartísticas, a partir del tópico $u t$ pictura poesis (Bergmann; Álvarez; Corbacho), la nueva historia política (Kantorowicz; Brendecke), la historia de las prácticas religiosas (Bartra; Christian, Religiosidad; Bray; González García, Imágenes) o la historia de la producción y circulación del conocimiento en el contexto de la expansión imperial (Bleichmar; Carrillo). Estos han subrayado la importancia de las imágenes como medios para deleitar, persuadir e instruir en la España del Siglo de Oro, destacando, entre otros aspectos, la afición renacentista por el maridaje de las artes (donde la poesía extremará los recursos visuales del lenguaje), las representaciones del rey como Argos, el uso de metáforas sobre la vista en las teorías del buen gobierno, la producción de imaginería religiosa realista y la difusión de imágenes y descripciones pormenorizadas de los territorios conquistados. Se trata, por lo tanto, de un contexto particularmente sensible en relación con los usos de la imagen, sobre todo por la conciencia 
que se tuvo respecto de su impacto comunicativo. Esto hace relevante la pregunta por la descriptio en Luis de Granada, ya que constituye una forma particular de ingresar a los debate sobre lo visual en la España de la segunda mitad del siglo XVI.

Se decidió trabajar con el Libro de la oración y la Retórica eclesiástica porque ambos desarrollan técnicas que tienen como objetivo alterar el estado de los oyentes o lectores a través del discurso, con el propósito de predisponerlos para contactar con Dios o convencerlos de vivir una vida virtuosa y alejada de vicios; es decir, persuadirlos para realizar una acción. Además, son los tratados más difundidos de Luis de Granada. El Libro de la oración y meditación, publicado por primera vez en Salamanca por Andrea de Portonaris en 1554, fue uno de los títulos más editados en el mundo

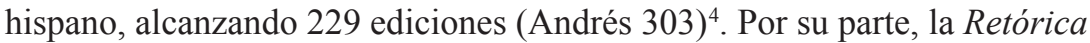
eclesiástica tuvo una enorme fama en toda Europa. A su primera edición, realizada en Lisboa por Antonius Riberius en 1576, le siguen la de 1578 en Colonia y Venecia, la de 1582 en Colonia, las de 1585 y 1588 en Milán y las de 1594 en Colonia y París; esto, sin contar todas las que se editaron durante los siglos XVII Y XVIII, además de sus traducciones al español y francés (López-Muñoz, "Un episodio" 28).

Este artículo sostiene que Luis de Granada elabora una teoría de la persuasión basada en el movimiento de las pasiones, ya que considera que la argumentación no es suficiente para doblegar a los oyentes a seguir un camino virtuoso y alejado de vicios. Según el autor, las técnicas más provechosas para este objetivo son la amplificación y la descriptio -o hipotiposis-, cuyo tratamiento retórico constituye una de las particularidades de su obra preceptiva. Se propone que la reactualización de estos preceptos antiguos se explica por las transformaciones ocurridas dentro de la religiosidad católica durante el siglo XVI. En concreto, me refiero a un giro afectivo, donde las emociones se consideraron como el instrumento fundamental para mover a devoción a los fieles y alejarlos del pecado. Esto se entiende mejor si se vincula con el contexto de crisis de la fe en la Iglesia Católica, donde fue necesario utilizar distintas herramientas para controlar y mantener a la población al interior

\footnotetext{
Este es un número considerable si se compara con otra de sus obras devocionales, Guía de pecadores, que alcanzó 81 ediciones; o El libro de la vanidad del mundo y Meditaciones devotísimas del amor de Dios, ambos de Diego de Estella, que tuvieron 26 y 19 ediciones, respectivamente.
} 
de su doctrina. La descriptio permitió hacer presente lo invisible mediante la descripción y el uso del lenguaje figurativo. Esto último es fundamental, ya que diferenció la teoría visual de Granada de la de importantes autores cristianos como Ignacio de Loyola. Para el dominico, el uso adecuado y colorido del lenguaje es suficiente para conmover y doblegar a los fieles, sin necesidad de otros recursos, como la pintura o la imaginería. De este modo, las pasiones y la descripción en la teoría de Granada nos muestran un punto de sutura entre el texto estudiado y su contexto de producción, permitiéndonos reflexionar sobre la importancia de las imágenes y la visión dentro de la cultura contrarreformista española.

\section{LA DESCRIPTIO EN LA TRADICIÓN RETÓRICA: UNA INTRODUCCIÓN A PARTIR DE LA RETÓRICA ECLESIÁSTICA DE LUIS DE GRANADA}

La descripción vívida es un recurso literario presente en toda la historia de las artes del discurso que consiste en representar verbalmente las circunstancias de una realidad de tal modo que pareciera que la estuviéramos viendo. Aunque en su Retórica Aristóteles no se refiere precisamente a ella, relaciona la elegancia oratoria con la capacidad de "hacer que el objeto salte a la vista"; es decir, que "<las expresiones $>$ sean signos de cosas en acto" (III, 1411b24) . En su Poética, el Estagirita profundiza más en este punto, aconsejando a los poetas lo siguiente: "es preciso estructurar las fábulas y perfeccionarlas con la elocución poniéndola ante los ojos lo más vivamente posible; pues así, viéndolas con la mayor claridad, como si presenciara directamente los hechos, el poeta podrá hallar lo apropiado" (XVII, 1455a21). Quintín Racionero señala en la edición crítica de la Retórica que este pasaje es importante, pues desde entonces, pasando por los autores post-aristotélicos, se asoció "el poner

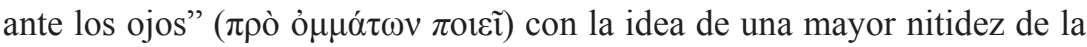

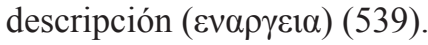

Los rétores romanos tradujeron el concepto de enárgeia ( $\varepsilon v \alpha \rho \gamma \varepsilon 1 \alpha)$ desarrollado por Aristóteles a distintos vocablos latinos, como illustratio (Cicerón), demonstratio (Rhetorica ad Herennium) y evidentia (Quintiliano)

En este artículo se trabajó con la edición y traducción de Quintín Racionero. Revisar esta edición para ver las variantes con la traducción de David W. Ross. 
(Plett 7-9). Este último autor es quien mejor desarrolla una teoría sobre la descripción vívida en la oratoria antigua, ya que en su tratamiento de la evidencia aumenta la definición del Estagirita, ofreciendo una serie de criterios formales que explican su funcionamiento retórico (Webb 47; Rodríguez 125). En Instituciones oratorias, Quintiliano da cuenta en dos ocasiones de este recurso. Primero, como una de las virtudes del ornato (más específicamente del adorno) que favorece la demostración de los argumentos ante el juez:

Pongamos primero entre las virtudes del adorno la enargia, la que más es evidencia, o como quieren otros, representación viva de la cosa, que claridad, por quanto esta se dexa ver, y la otra evidencia la cosa. Es grande virtud el proponer la cosa con unos colores tan vivos, como si la estuviéramos viendo. Porque para lograr su efecto la oración, no basta que lo que decimos llegue a los oídos del juez, contando la cosa simplemente; sino que debemos pintársela muy al vivo (VIII, 3, v).

Y segundo, como una de las diez figuras de sentencia que sirven para aumentar los afectos:

Pero aquello de poner una cosa, como dice Cicerón, delante de los ojos, se suele hacer, quando se cuenta un suceso no sencillamente, sino que se demuestra como sucedió; y no todo, sino por partes: lo qual comprehendimos en el libro anterior en la evidencia, cuyo nombre dió Celso también á esta figura. Otros la llaman hypotyposis, esto es, una pintura de las cosas hecha con expresiones tan vivas, que más parece que se percibe con los ojos, que con los oídos (IX, 2, II).

Según Quintiliano, las figuras de sentencias hacen creíbles los relatos al introducirse poco a poco en los ánimos de los jueces. Como se observa, en ambos casos se relaciona la vivacidad del discurso con la veracidad del argumento, la cual, a su vez, se vincula con un lenguaje visual capaz de generar resultados afectivos en el receptor. Adolfo Rodríguez Posada señala que Quintiliano agrega tres modos fundamentales de alcanzar la enárgeia a la teoría aristotélica ${ }^{6}$ : cuando ponemos una imagen viva de las cosas a través

6 En Aristóteles encontramos, principalmente, la prosopopeya y la metáfora, las que también están presentes en la propuesta de Quintiliano. 
de las palabras ${ }^{7}$; cuando representamos visualmente un asunto a partir de las muchas circunstancias que lo conforman ${ }^{8}$; cuando la mutua correspondencia de dos cosas las pone a la vista al mismo tiempo ${ }^{9}$ (126). Estas distinciones llevan a Rodríguez Posada a concluir que para Quintiliano "la hipotiposis tiene lugar cuando el orador, historiador o poeta representan la realidad en función de la conceptualización del referente en términos plásticos [...]; pero, asimismo, presentando ante el oyente/lector cada cosa de por sí de manera detallada" (127). Es decir, una definición que tiende a destacar la capacidad pictórica del lenguaje y otra que remite a su potencial para hacer presente lo ausente a partir de la amplificación de sus circunstancias.

Los autores griegos del periodo romano utilizaron el término écfrasis

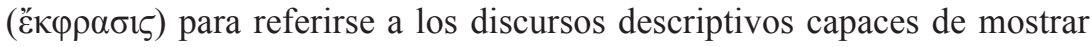
vívidamente las circunstancias de un asunto ${ }^{10}$. Su tratamiento retórico se difundió, principalmente, a través de los ejercicios escolares conocidos como progymnasmata, los escolios de las obras del canon clásico y algunos manuales de retórica, como el de Menandro y el de Hermógenes de Tarso sobre los tipos de estilo (Webb 39). El primer registro del término se encuentra en los progymnasmata de Elio Teón, contemporáneo de Quintiliano, cuya definición se repetirá, palabra por palabra, en las versiones del pseudo-Hermógenes, Aftonio de Antioquia y, en menor medida, Nicolás de Myra (Webb 46). Si bien estos textos conforman un grupo unificado, considerando los cuatro siglos que transcurrieron entre Teón y Nicolás, también experimentaron transformaciones en sus definiciones y ejemplos. En esta línea, es importante el reconocimiento que hace Nicolás de la utilidad de las esculturas y pinturas como tema para la écfrasis, otorgándole la capacidad de establecer una relación intermedial, de carácter intersemiótico, entre un discurso y una representación plástica ${ }^{11}$. Se trata de la definición de écfrasis que han utilizado los historiadores del arte

\footnotetext{
"La primera es, quando con palabras ponemos una viva imagen de la cosa" (Quintiliano VIII 3, v).

"A veces de muchas circunstancias resulta la pintura de lo que intentamos representar" (Quintiliano VIII 3, v).

9 "Son muy del caso los símiles para aclarar la cosa" (Quintiliano VIII 3, v).

10 Según Ruth Webb, los tratados de retórica posclásicos no utilizaron esta palabra para referirse al acto de describir, sino que, como Dionisio de Halicarnaso, recurrieron a

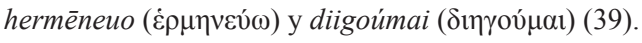

11 Esta forma de écfrasis fue denominada por Luz Aurora Pimentel como écfrasis referencial, ya que lo que se describe a través del discurso tiene un referente extradiscursivo que, a su vez, es representación de otra cosa (207).
} 
y críticos literarios desde la segunda mitad del siglo xx, como Leo Spitzer y James A. W. Heffernan, quienes llegaron a oscurecer totalmente su significado más genérico (Pimentel 206) ${ }^{12}$.

Es importante mencionar, antes de avanzar, que esta acepción tiene base en una de las dimensiones de la definición inicial, también presente en Quintiliano, que refiere a la capacidad pictórica de las palabras para hacer visible un asunto. Es decir, el potencial para generar cuadros imaginarios en la mente de los receptores, no necesariamente a partir de una descripción detallada, entendida como parte del proyecto de la amplificación. Esta distinción coincide, a su vez, con la que realiza Luisa López Grigera entre descripción estática, que representa objetos como si fueran cuadros, y descripción dinámica, que da cuenta de las acciones en tanto escenas en movimiento (135).

Si bien los autores latinos y bizantinos elaboraron una teoría de la descripción vívida (evidencia, hipotiposis, écfrasis), no fue sino hasta la llegada de la retórica renacentista que alcanzó mayor extensión y relevancia, cuando se perfilaron más nítidamente las diferencias entre narración y descripción (Rodríguez 126). Con excepción de los ejercicios retóricos de Hermógenes, que circularon en la Antigüedad tardía y la Edad Media a partir de la traducción latina de Prisciano, los progymnasmata no se difundieron en Europa occidental sino hasta principios del siglo XVI, con las primeras ediciones y traducciones de Aftonio y Teón, realizadas por Rodolfo Agrícola y Joaquín Camerario, respectivamente (Arcos y García 320). Estos alcanzaron una enorme fama en el contexto europeo occidental, visible, entre otras cosas, a partir de sus numerosas ediciones y reimpresiones, siendo, incluso, la base de la enseñanza retórica en los manuales de la Ratio Studiorum (Pérez LVIII).

Desde el siglo XVI, es posible reconocer la utilización del término descriptio para referirse a lo que los autores antiguos llamaron evidentia, hypotyposis y ekphrsais. Este es el vocablo que se utiliza en las traducciones latinas de los progymnasmata y, como indica Casilda Elorriaga del Hierro, también es el que aparece en los manuales retóricos españoles del Renacimiento. La autora estudia los tratados que van desde 1500 a 1565, identificando dos periodos distintos. El primero, que abarca hasta 1550, se caracterizó por un

12 Dentro de los teóricos contemporáneos, W. J. T. Mitchell ha retomado, levemente, la dimensión más genérica de la écfrasis como descripción vívida, haciendo hincapié en la capacidad del lenguaje para hacer presente la imagen ausente, en donde lo visual sería tematizado como lo "otro" del lenguaje (Teoría 140). 
paulatino interés hacia el estudio de la descripción, asociado principalmente a la enárgeia como forma de prueba. Esto se profundizó con Luis Vives y Miguel de Salinas, quienes, a partir de distintas influencias, comenzaron a destacar la importancia de la descriptio en el discurso narrativo, ligado a la enumeración de las circunstancias. A su vez, desde mediados del siglo, y a partir de los tratados de Antonio Lulio y Juan Lorenzo Palmireno, se completa aún más la teoría descriptiva renacentista, destacando su papel elocutivo y su relación con otras figuras de sentencia que permiten poner un asunto ante los ojos. Para Elorriaga, en este periodo Cicerón dejó de ser el modelo para la inventio de la descripción y el foco se trasladó hacia la imitación de modelos poéticos, principalmente Homero y Virgilio.

En la Retórica eclesiástica, Luis de Granada también utiliza el término descripción para dar cuenta de la representación vívida de las cosas y personas; sin embargo, en su tratamiento no recurre a sus contemporáneos, sino que su modelo indiscutible es Quintiliano ${ }^{13}$. Ahora bien, y como es costumbre en las retóricas sagradas, difiere en los ejemplos, ya que Granada remite a fuentes cristianas, como Gregorio Nacianceno, Cipriano de Cartago, Gregorio de Nisa y Juan Crisóstomo. Es necesario señalar que la asociación entre la traducción latina de la evidentia (o écfrasis) como descriptio y los preceptos de Quintiliano no es exclusiva del dominico. Uno de los primeros ejemplos aparece en algunas ediciones de los progymnasmata de Aftonio que, desde 1550 , incluyeron en la definición de descripción una nota al margen que remite al capítulo 3 del libro VIII de Instituciones oratorias $^{14}$. En este apartado, como se mencionó anteriormente, el autor latino trabaja la evidencia como una de

13 La influencia de Institutio oratoria es fundamental en todas las obras de Granada, pero sobre todo en libro III de su Retórica eclesiástica, dedicada al tratamiento de las pasiones. Manuel López-Muñoz, quien estudia y cuantifica el uso de los autores romanos en la preceptiva del dominico, señala que de las 17 referencias latinas que utiliza el autor, 12 corresponden a la obra de Quintiliano (Fray Luis 148).

14 Me refiero, al menos, a la edición de Lyon de 1555, impresa por Antonio Vicente, donde se reproduce la traducción mixta de Rodolfo Agrícola y Juan María Cataneo, con los comentarios de Reinhard Lorich. En la nota se indica lo siguiente: "Descriptiōis summa est virtus, inquit Quint. li. 8. capite 3. facillimè enim id accipiūt animi, quod agnoscut". Esta nota no se encuentra presente en ediciones previas, como la de Juan María Cataneo (1507), Gentian Hervet (1520), Rodolfo Agrícola (1532), Antonio Bonfine (1538), Reinhard Lorich (1542). Sería interesante pesquisar esta nota; sin embargo, esto no se puede realizar para los efectos de esta investigación, pues requiere de una búsqueda extensiva por distintas bibliotecas y repositorios virtuales, debido al enorme número de ediciones de esta obra que se realizaron en todo Europa durante el siglo XVI. 
las virtudes del ornato. No obstante, la relación entre descripción y evidencia que propone la nota mencionada no es idéntica a la que desarrolla Luis de Granada, cuyas particularidades se presentarán a continuación.

En el libro III de su Retórica eclesiástica, dedicado a la amplificación retórica, Luis de Granada define la descripción de la siguiente manera:

Descripción es cuando no exponemos sumaria ni ligeramente algo que es o ha ocurrido, sino que lo ponemos a la vista teñido de todos los colores para que el oyente o el lector capte como en un teatro lo que ya se le ha puesto fuera de sí. Los griegos la llaman hypotyposis porque perfila una representación de las cosas, supuesto que esta denominación es genérica para todos los casos en que algo se pone ante la vista (Los seis III, 6, 297).

Esta definición es similar a la que entrega Quintiliano de la evidencia como figura de sentencia en el libro IX de Instituciones oratorias. Es decir, como un modo de representación detallada de las circunstancias de una cosa que permite que el receptor se sienta parte de la escena descrita. Esto remite, como ya vimos, a la definición de descripción dinámica de Luisa López Grigera, en tanto que representa las acciones como si fueran obras dramáticas ("como en un teatro"). En este punto, es importante destacar que Luis de Granada profundiza la relación entre amplificación y descripción, que ya estaba presente en Quintiliano, presentando a esta última como una de las figuras más útiles para la amplificación retórica:

Y entre los ornamentos de la elocución que mayor utilidad tienen para la amplificación, en gran número se cuentan las descripciones de cosas y personas y, aun cuando vayan también para otros cometidos, toda vez que se suele dar este tipo de descripciones por causar deleite, es, no obstante, frecuentísimo su uso al amplificar o exagerar algo (Los seis III, 6, 297).

La importancia de la descripción vívida en la teoría granatense, por lo tanto, se explica por la relevancia que le entrega a la amplificación en su teoría de la persuasión, la cual, a su vez, se entiende a partir de la preminencia que tienen las emociones dentro de su Retórica eclesiástica ${ }^{15}$. Se puede pensar,

15 Es necesario mencionar que aunque todos los tipos de descripción permiten amplificar un asunto, no todas lo hacen vívidamente. En la teoría de Granada, por ejemplo, 
de este modo, que la relación entre emociones, amplificación y descriptio, es un aporte importante de Granada a la teoría de la descripción en la retórica renacentista:

Y, siendo como es que la amplificación está diseñada para conmover los estados de ánimo, nada los remueve más que si algo se expresa en palabras de tal manera que se antoje, no tanto que se dice cuanto que se hace y se pone ante los ojos, porque conocido es que todos los estados de ánimo se ven sobremanera concitados por la envergadura de lo que se pone ante los ojos, lo cual es cierto que ocurre en las descripciones, ya sea de cosas, ya de personas (Los seis III, 6, 297).

Ahora bien, no es casual que Granada haya formulado esta teoría de la descripción en la Retórica eclesiástica. La obra del dominico surge en un contexto donde se difunde una nueva religiosidad afectiva que desarrolló distintas técnicas para interpelar emocionalmente a los feligreses apelando a sus sentidos. La mayoría de las festividades públicas, tanto religiosas como seculares, destacaron por su carácter multisensorial debido al uso de imágenes, esculturas, música, discursos, representaciones teatrales, inciensos, entre otros. Dentro de este contexto, las imágenes y el sentido de la vista fueron asociados estrechamente con la persuasión, debido a su potencial sugestivo. La Iglesia contrarreformista, temerosa de sus vecinos del norte, convirtió la imagen en un arma indispensable para mantener a la población en la religión católica y reconquistar a quienes se habían alejado de la doctrina (Gèlis 30).

\section{LA CONSIDERACIÓN COMO DESCRPTIO EN EL LIBRO DE LA ORACIÓN DE LUIS DE GRANADA}

Las imágenes como instrumentos de comunicación han estado presentes en toda la historia de la Iglesia cristiana; sin embargo, no han tenido la misma función ni relevancia a lo largo del tiempo. En el contexto estudiado, y como se profundizará más adelante, existió un amplio debate en torno al

la sermocinación y conformación no recurren a un lenguaje visual para "hacer presente" lo descrito. La primera lo hace asignando un discurso a un personaje, utilizando un estilo que le debiese ser propio; mientras que la segunda le atribuye una acción, expresión o discurso a un objeto o ente inanimado (Los seis III, 8, 321-329). 
uso de imágenes dentro y fuera de la Iglesia, siendo un tema importante en los concilios ecuménicos realizados en Trento entre 1545 y 1563 . En la sesión XXV, realizada los días 3 y 4 de diciembre del último año, los obispos discutieron sobre los usos legítimos de las imágenes, decretando que debían seguir las costumbres y tradiciones de la Iglesia, ya que solo así podrían ser verdaderamente útiles. Se precisó, además, que su veneración no se explicaba por una supuesta divinidad intrínseca, como en el caso de los ídolos, sino por el honor de lo que representaban ${ }^{16}$ :

[S]e deben tener y conservar, principalmente en los templos, las imágenes de Cristo, de la Virgen madre de Dios, y de otros santos, y que se les ha de tributar el correspondiente honor y veneración; no porque se crea que hay en ellas divinidad o virtud alguna por la que merezcan el culto; o que se les deba pedir alguna cosa; o que se haya de poner la confianza en las imágenes, como hacían en otros tiempos los gentiles que fundaban su esperanza en los ídolos; sino porque el honor que se da a las imágenes, se refiere a los originales representados en ellas; de suerte que adoremos a Cristo por medio de las imágenes que besamos, y en cuya presencia nos descubrimos y arrodillamos (Tejada y Ramiro 400-401).

En el párrafo siguiente, se da cuenta de dos tipos de imágenes que son provechosas para la Iglesia: por un lado, las que enseñan las historias de la redención, instruyendo y recordando a los feligreses los fundamentos de la fe, que llamaremos imágenes doctrinales; y por el otro, "las que exponen a los ojos de los fieles los saludables ejemplos de los santos" y los milagros de Dios con el propósito de modificar sus vidas y costumbres, que denominaremos imágenes devocionales (Tejada y Ramiro 401). En concreto, la diferencia entre ambas es que la primera narra una historia con el propósito de enseñar un principio doctrinal, mientras que la segunda describe pormenorizadamente una escena que se quiere dejar registrada en la memoria de los fieles. Durante el periodo estudiado, predominó el uso de la imagen devocional por sobre la doctrinal, demostrando un cambio de estrategia en los métodos persuasivos de la Iglesia Católica. Esto coincidió, también, con el paso de una predicación doctrinal (docere) a una devota y afectiva (movere). Manuel López-Muñoz

16 Según Juan Luis González, el origen de este principio se encuentra en El Espíritu Santo de Basilio de Cesárea, y se reactualiza con fuerza a partir de la contrarreforma católica ("Retórica" 48). 
denominó esta predicación como vía tridentina, asumida por gran parte del humanismo erasmista de los reinos católicos, donde se privilegió el uso de las emociones para deleitar y mover a los fieles, como fue el caso de Luis de Granada (Fray Luis 41-42) ${ }^{17}$.

Desde un plano discursivo, el poder persuasivo de las imágenes ya era conocido en las retóricas antiguas, tal como lo vimos en el apartado anterior. Según un grupo de investigadores, esto volvió a encontrar vigencia en el siglo XVI debido a la nueva religiosidad afectiva que alcanzó cada vez más adeptos, incluso en las altas jerarquías eclesiásticas (Ledda; González García, Imágenes). El propio Juan de Ávila, al reflexionar sobre la redención de Cristo y el poder de las imágenes para conmover a los feligreses en Audi Filia, señala que "quando quieren sacar alguna imagen, para hacer llorar, vístenla de luto, y pónenla todo lo que incita a tristeza. Pues decidme: ¿qué fue el intento de Pilato en sacar a Christo a ser visto del Pueblo?" (Obras del venerable 197). Según José Antonio Maravall, su uso seductor del espectáculo fue una táctica deliberada en una lucha de poder por manipular y controlar a la población ante fuerzas insurgentes (166-68).

El cristocentrismo de la religiosidad del periodo también fue un factor que colaboró en la difusión del potencial persuasivo de las imágenes. Se trató de un contexto donde se renovaron tradiciones tardomedievales, junto con una evidente atención por el Cristo de la Pasión ${ }^{18}$. Al respecto, Jacques Gèlis indica que era fundamental que los devotos pudieran ver las marcas de las heridas de Jesús, consideradas como huellas corporales de su vida terrenal. No era suficiente saber que había muerto en la cruz, atormentado por inmensos sufrimientos corporales y espirituales, sino que también había que poner su cuerpo, dolido y humillado, ante los ojos de los fieles (30-38). Se difundieron, por lo tanto, numerosas representaciones pictóricas y escultóricas sobre el

17 En paralelo, se desarrolló la vía protestante, cuyas bases retóricas se pueden encontrar en las teorías de Felipe de Melanchton y la fuerte pervivencia de la homilética medieval centroeuropea, principalmente centrada en la educación doctrinal a partir de argumentos racionales (Fray Luis 52-56).

18 William Christian señala que la popularidad de las imágenes de la Pasión de Cristo y el sufrimiento de María llegaron a tal nivel que, entre ambas, sumaban 47 de las 73 nuevas devociones que se generaron con la creación de santuarios en el reino de Felipe II (Religiosidad 221). Además, da cuenta de un aumento significativo de las denuncias en la Inquisición de Cuenca por declaraciones heréticas en torno a la redención de Cristo y la Eucaristía, revelando la vigilancia en torno a estos temas doctrinales (Religiosidad 229). 
Cristo crucificado y flagelado, así como la escenificación de los autos de fe en las iglesias y fiestas religiosas, como la del Corpus Christi (Christian, Religiosidad 229). También fueron significativos los grabados producidos por la imprenta, sobre todo para los sectores menos adinerados. Por este medio se propagaron importantes iconografías sobre la Pasión de Cristo, como la escena de la flagelación que se representa en varios grabados de Jerónimo Wierix, importante grabador flamenco de fines del siglo XVI y primera mitad del XVII. Incluso, grabados del siglo Xv de Alberto Durero, que se reprodujeron en los siglos posteriores ${ }^{19}$.

Las imágenes, ya sea como pinturas, esculturas o grabados, sirvieron para apelar a la emoción de los fieles y moverlos a una vida devota. Estas no se restringieron únicamente a los espacios de contemplación, sino que también estuvieron presentes en la vida cotidiana de los fieles y en las casas de muchas familias, a través de pinturas o pequeñas estampas religiosas. Además, recordemos que aunque estas se resguardaban principalmente en iglesias, conventos y palacios reales, en las procesiones y fiestas públicas se sacaban con el propósito de aportar al escenario piadoso. Por su parte, la literatura ascética y la oratoria sagrada también valoraron la importancia de la imagen y lo visual en la persuasión, como se observa en las obras de Luis de Granada estudiadas en este trabajo.

La literatura ascética, ya sea en los manuales de oración metódica o en los libros devocionales, manifestó tempranamente una inclinación por el uso de imágenes materiales y mentales en la oración ${ }^{20}$. Antes de avanzar, es necesario explicar esta doble concepción de las imágenes, que se remonta a los tiempos de la Antigüedad. En el pensamiento helénico, la visión podía ser física, con los ojos corporales, o mental, con los ojos del intelecto (Jay 28-30). Esta división se mantuvo durante toda la Edad Media a través de los

19 El antecedente directo de estas manifestaciones fue la difusión de las huellas de la vida terrenal de Cristo durante el siglo XIV. En concreto, se hace referencia al culto a la Verónica, o vera icon, y el Santo sudario (síndone). Durante fines de la Edad Media hubo muchas iglesias que reclamaron tener una reliquia de estas características, lo que generó grandes debates al interior de las autoridades eclesiásticas. No indagaremos en estos debates, ya que no es parte de los objetivos de esta investigación. Para quienes quieran profundizar en este punto, revisar el trabajo de Jacques Gèlis que se cita en este artículo.

20 Las técnicas necesarias para alcanzar la fase introspectiva de la oración se conocían desde la Edad Media y se repitieron en el siglo XVI español, donde la expresión "dibujar en el corazón" se tomó como sinónimo de la introspección icónica, configurando un paralelo con el acto material de fabricar imágenes (González García, Imágenes 393). 
autores cristianos, como Tomás de Aquino, quien sostuvo que la visión tiene dos acepciones: "la primera concierne a la percepción a través del órgano de la vista; y la segunda se aplica a la percepción interna de la imaginación o intelecto" (Stoichita 12). Este último significado es el más importante para esta investigación, ya que se relaciona directamente con las facultades retóricas de la descriptio. Ahora bien, es necesario señalar que estos dos tipos de visión se complementan, ya que la imagen interna utiliza a la externa como modelo. Esto ya lo advertía Juan de Ávila en Audi Filia:

Y sabed, que, pues el altísimo e invisible Dios se hizo hombre visible, para que con aquello visible nos metiese adentro, donde está lo invisible; no se debe pensar sino que fue muy provechosa cosa, mirarle con ojos corporales, para poderle mirar con los espirituales, que son de la fe, si la malicia de quien lo miraba, no lo impedía: y cierto, todo lo corporal del Señor era muy ordenado, y tenía una particular eficacia para ayudar al corazón piadoso a levantarse a las cosas espirituales. [...] y a este intento nuestra Madre la Iglesia, y con mucha razón, nos propone imágenes del cuerpo del Señor, para que, despertados por ellas, nos acordemos de su corporal presencia, y se nos comunique algo, mediante la imagen, de lo mucho que se nos comunicará con la presencia. Y pues me trae provecho una imagen pintada en un palo, fuera de mí, también lo traerá la que fuere pintada en mi imaginativa, dentro de mí, tomando por escalón para pasar adelante (Obras del venerable 5).

No es necesario alejarse de Luis de Granada para encontrar ejemplos sobre esta situación. El autor fue un prolífico escritor ascético y uno de los más importantes de España, sobre todo por su estilo e impacto en el resto de la cristiandad europea. José Luis Abellán señala que Granada fue el mayor representante de la devoción cristocéntrica de la segunda mitad del siglo XVI, ya que supo sistematizar teológicamente el conjunto simbólico que representaba Cristo (278-281). Su propuesta de meditación se basa en el valor que le asigna a la consideración, llegando a sostener que su ausencia en los fieles es la causa de los males que hay en el mundo, ya que es esta la que permite alejar a las personas del pecado (Libro 5). El autor la define como un ejercicio "que desencierra lo encerrado y despliega lo encogido y aclara lo oscuro [...] y, así, esclareciendo nuestro entendimiento con la grandeza de los misterios, inclina nuestra voluntad, cuando es de su parte, a vivir conforme a ellos" ("De la oración" 4). Una meditación realista que permite "desmenuzar estas cosas [los misterios] para sentir y ver lo que dentro dellas 
ay" (Libro 5v). Según Granada, necesita ser guiada y supervisada, en este caso por un texto que dice hacia dónde mirar, qué es lo digno de observar y cuál es su envergadura.

La predicación, por su parte, fue uno de los espacios donde tuvo mayor influencia la religiosidad afectiva y visual que se desarrolló en la España de los siglos XVI y XVII. Esto se debe a que la oratoria sagrada no solo se conformaba por el sermón del sacerdote, sino que también buscaba generar un ambiente multisensorial que apelara a todos los sentidos de los fieles. Juan Luis González ha realizado numerosos aportes en torno a la importancia de las pinturas y esculturas en los sermones, principalmente a partir de las figuras de Hortensio Félix Paravicino y Juan Bautista Escardó ("Retórica"). Sobre la predicación, el autor señala:

[L]a configuración del templo, los objetos de culto, los cuadros y las imágenes de bulto ayudaban a hacer del sermón predicado lo que la cultura silenciosa era incapaz de restituir: un acto de comunicación completo que postulaba la participación intelectual y afectiva del oyente y en el que éste comprendía en cada momento su carácter ritual o sagrado (González García, Imágenes 360).

Luis de Granada no fue el único, ni mucho menos el primero, en considerar la importancia de la imagen como medio de persuasión en el catolicismo contrarreformista. Se suele reconocer a los Ejercicios espirituales de Ignacio de Loyola como la principal codificación de la espiritualidad ascética y su composición de lugar como una de las teorías más influyentes sobre la imagen y lo visual en el mundo católico (Fabre). Esta última se puede definir como una forma de visualización imaginativa que tiene como propósito llevar al fiel a un estado de docilidad que le permita interiorizar la doctrina cristiana. Para ello, se debía recurrir a la propia memoria sensitiva e intelectual del orante a partir de un tema apenas abocetado discursivamente. Es el propio individuo, por lo tanto, quien debe elaborar una representación imaginativa de la escena evocada. Al respecto, Ignacio de Loyola señala sobre los ejercicios de la primera semana:

El primer preámbulo es composición, viendo al lugar. Aquí es de notar, que en la contemplación, o meditación visible, así como contemplar a Christo Nuestro Señor, el qual es visible, la composición será ver con la vista de la imaginación el lugar corpóreo donde se halla la cosa que quiero contemplar. Digo el lugar corpóreo, así como un templo 
o monte, donde se halla Jesuchristo, o Nuestra Señora, según lo que quiero contemplar (Ejercicios 29).

De este modo, los ejercicios espirituales dependían de "los recuerdos de imágenes reales y del conocimiento almacenado de ellas, y no de la viveza empática de las descripciones composicionales. [...] De una forma u otra, la compositio loci radicaba en el arte de la memoria, en la doble creación de lugares e imágenes agentes" (González García, Imágenes 433) ${ }^{21}$. En definitiva, la propuesta era que con poca información discursiva los devotos pudieran imaginar la escena, recurriendo a sus propios archivos mentales. Se puede deducir, por tanto, que la importancia concedida al lenguaje y su potencial transformador fueron más débiles que en la propuesta granatense, ya que en Loyola importaba más la creación de dispositivos sensoriales que movieran y sensibilizaran a los fieles, como la imaginería religiosa (Cilveti 190-194) ${ }^{22}$. Esto también se puede observar al comparar los Ejercicios espirituales con el Libro de la oración, en tanto que el primero carece de materiales para la meditación, mientras que el segundo abunda en ellos. A su vez, si consideramos que el manual de Loyola fue escrito en latín, mientras que el de Granada en castellano, podemos entender que tenían públicos y propósitos distintos. El primero se dirigía a sacerdotes y guías espirituales, mientras que el segundo estaba destinado a un lector cristiano más amplio (Pérez García 39).

Tanto la descriptio como la consideración permiten suponer que el autor pensó que el lenguaje tenía el potencial suficiente para incidir en sus receptores, modificando, por ejemplo, sus decisiones a través de la persuasión. Sin embargo, hay que precisar que no se trata de cualquier tipo de lenguaje, sino de aquel con artificio retórico o, como lo llamaríamos hoy en día, literario. Esto se observa en la importancia que le entrega el autor a la elocutio en su Retórica. Es precisamente la confianza en este tipo de lenguaje lo que marcará la particularidad de la retórica granatense y, en términos más generales, de su teoría sobre la persuasión. En este sentido, se busca sostener que la descriptio

21 No quisiera profundizar en este punto, pues no es el objetivo principal de este trabajo; sin embargo, el lector interesado en los vínculos entre la visión imaginativa ignaciana y las técnicas de la memoria artificial de los tratados de retórica antigua puede revisar el artículo de Fernando Rodríguez de la Flor que se incluye en la bibliografía.

22 Para profundizar en la teoría visual de Ignacio de Loyola se recomienda revisar los trabajos de Darío Velandia Onofre que se citan en este artículo, ya que presenta una mirada actualizada sobre el tema ("Word and Image"; Hacia una teología 135-168). 
fue la adaptación retórica que hizo Granada del contexto espiritual y afectivo que le tocó vivir y en el cual lo visual adquirió un importante prestigio como medio de comunicación. Para Granada, a diferencia de Loyola, el lenguaje bien utilizado tenía la facultad de poder visualizar determinadas escenas en los "ojos interiores" de los receptores del mensaje. Esta particularidad de su obra se puede observar en la descripción que realiza de un pasaje de la Pasión de Cristo:

Entra pues ahora, anima mía, con el espíritu en el pretorio de Pilatos, y lleva contigo las lágrimas aparejadas, que serán bien menester para lo que verás y oirás. Mira como aquellos crueles y viles carniceros desnudan al Salvador de sus vestiduras con tanta inhumanidad, sin abrir él la boca, ni responder palabra a tantas descortesías como allí le harían. Mira como luego atan aquel santo cuerpo a una columna, para que así lo pudiesen herir a su placer donde y como ellos más quisiesen. Mira cuando solo estaba el Señor de los Ángeles entre crueles verdugos, ni valedores que hiciesen por él, ni aun siquiera ojos que se compadeciesen de él. Mira como luego comienzan con grandísima crueldad a descargar látigos y disciplinas sobre aquellas delicadísimas carnes, y como se añaden azotes sobre azotes, llagas sobre llagas, heridas sobre heridas. Allí verás luego teñirse aquel santísimo cuerpo de cardenales, rasgarse los cueros, reventar la sangre, y correr a hilos por todas partes. Mas sobre todo esto, qué seria ver aquella tan grande llaga que en medio de las espaldas estaría abierta, adonde, principalmente caían todos los golpes? (Libro 44).

Este fragmento no pretende narrar un hecho o explicar un principio doctrinal, sino describir un suceso de modo realista para que los destinatarios sientan que son parte de la escena descrita. Se observa, en este sentido, una preocupación por generar una sensación de presencia, la que se propone leer en relación con un aspecto fundamental del contexto religioso y cultural que se ha venido retratando. En concreto, se hace referencia al vínculo entre una espiritualidad preocupada por la presencia física del cuerpo de Cristo y el principio teológico de la transubstanciación y el sacramento de la Eucaristía, cuya doctrina se definió y robusteció en las sesiones del Concilio de Trento. Estos dogmas sacramentales buscaron reafirmar la presencia verdadera del cuerpo y sangre de Cristo en la sustancia del pan y el vino, mediante la consagración del sacerdote. Incluso, se hizo común durante el periodo estudiado el levantamiento de la hostia y el vino como testimonios de la conversión (Barasch 301; Gèlis 46). Esto es particularmente importante si lo pensamos en relación con la 
crisis religiosa del siglo XVI, ya que los teólogos protestantes rechazaron el dogma de la presencia real de Cristo en las sustancias eucarísticas. Solo creían en la presencia simbólica y el resto lo asociaban a la idolatría ${ }^{23}$. Me parece pertinente, en este sentido, pensar en la descriptio, la consideración y la Eucaristía como tres formas de hacer presente lo ausente, en un contexto donde precisamente se estaban repensando las técnicas de persuasión y control en el catolicismo contrarreformista.

\section{PALABRA E IMAGEN EN LA TEORÍA DE LA PERSUASIÓN DE LUIS DE GRANADA}

Lo primero que habría que señalar sobre la relación entre palabra e imagen en la teoría granatense es que no se observan grandes diferencias entre ambas, al menos entendidas en su acepción moderna; es decir, como dos medios de comunicación antagónicos. Siguiendo a Mitchell, se podría sostener que no existen medios puros, ya que en ellos se relacionan distintos elementos sensoriales y semióticos que no son simples extensiones de los sentidos, sino operadores simbólicos complejos (Mitchell, "No existen"). Si bien Luis de Granada no lo postula de esta forma, es posible sostener que tiene consciencia de la heterogeneidad de los medios y del provecho que puede sacar de esta situación, principalmente por el valor que le asigna al lenguaje retórico y a la actio en su teoría de la predicación. De ahí que sea posible cuestionar la oficiosidad para el periodo estudiado de la oposición entre palabra e imagen como dos sistemas antagónicos de representación que necesitan traducirse. Ahora bien, esto no quiere decir que en la teoría de Granada -y, por extensión, en la cultura española del siglo XVI-, no existiera una distinción entre ambas, solo que, y siguiendo a Mitchell, “esas diferencias son mucho más complejas de lo que puede parecer a primera vista, apareciendo dentro de los medios

23 Algo similar se observa en la literatura mística y ascética española del Siglo de Oro, la cual, según algunos investigadores, se sustenta en la nostalgia que produce la distancia entre la presencia de la Palabra y la ausencia del cuerpo de Cristo (De Certeau; Kristeva; Cuevas). Del mismo modo, es relevante mencionar que en el plano secular se enfrentó un problema similar al anterior. A medida que los territorios del Imperio español se ampliaban durante los reinados de Carlos I y Felipe II, se hizo necesario "hacer presente" al rey en los territorios lejanos, para lo cual se recurrió al poder del ceremonial y, particularmente, el uso de imágenes y emblemas (Osorio; Brendecke; Salazar). 
tanto como entre ellos, y pudiendo cambiar a lo largo del tiempo, a medida que cambian los modos de representación y las culturas" (Teoría 11).

A partir de lo anterior, es posible pensar que la oposición entre palabra e imagen, escritura y pintura, debiese ser repensada a partir de la oposición entre los procedimientos miméticos narración y descripción, presentes en ambas. De este modo, y según lo revisado en este artículo, el desafío de la cultura letrada renacentista no fue precisamente vencer el hiato entre palabra e imagen, como si existiera una alteridad radical entre ellas (Mitchell, Teoría 143), sino que intentar hacer presente lo ausente, problema que, como hemos visto, fue crucial durante el periodo estudiado. Para ello, más que elaborar un lenguaje visual que traduzca una imagen en palabras, fue necesario recurrir a un discurso figurativo que permitiera "mostrar" mediante la descripción. De este modo, se observa una confianza en el potencial transformador (es decir, persuasivo) del uso correcto del lenguaje, que incluso tendría la capacidad de superar la ausencia divina, permitiendo a los fieles experimentar el dolor de Cristo a través de una descripción adecuada. Esto concuerda, a su vez, con el tipo de imágenes (pinturas y esculturas) que circularon en el contexto contrarreformista, caracterizadas por su realismo y vivacidad, donde predominó la descripción antes que la narración. Es decir, imágenes devocionales por sobre las doctrinales, donde se representaban algunas escenas con una profunda preocupación por los detalles y la representación realista (Bray 30-56).

En este sentido, se podría sostener que las imágenes no necesariamente sirven para "mostrarnos" algo, sino que también pueden contar historias o fijar argumentos, del mismo modo que el lenguaje verbal/oral no es exclusivamente narrativo. El punto central de este asunto, retomando a Mitchell, es que "los actos comunicativos y expresivos, la narración, el argumento, la descripción, la exposición y otros así llamados actos de habla no son específicos de un medio" (Teoría 144). Por lo tanto, la división entre palabra e imagen es más bien arbitraria y producto de las pretensiones disciplinares actuales. Entonces, la pregunta que habría que hacer es: ¿qué tipo de lenguaje o acto comunicativo predominó en este periodo y por qué razones? La teoría de la persuasión y la descriptio de Luis de Granada nos entrega una respuesta. Para el autor, era necesario elaborar descripciones excesivamente detalladas a partir de un lenguaje figurativo que nos permitiera imaginar, con los ojos mentales, aquello que se estaba describiendo. Mediante el uso del lenguaje, los predicadores y autores ascéticos debían ser capaces de trasladar a los oyentes y lectores a la escena referida. De este modo, la descriptio, según la perspectiva de Granada, no sería una experiencia óptica, aunque sí una experiencia de la 
imagen. Las condiciones de su claridad dependerán, exclusivamente, de las habilidades que tenga el emisor para describir y hacer que los oyentes o lectores vivan lo descrito.

\section{CONCLUSIONES}

En este artículo se propuso que Luis de Granada elaboró una teoría de la persuasión centrada en el movimiento de las pasiones, donde la descriptio ocupó un lugar fundamental. Para el autor, el lenguaje verbal es capaz de hacer que los receptores experimenten la escena descrita - principalmente ligada a la Pasión de Cristo- como si ellos mismos la estuviesen viviendo. La importancia que Granada le asignó al lenguaje retórico caracterizó su teoría sobre la persuasión. A diferencia de la composición de lugar de Ignacio de Loyola, donde se recomienda un lenguaje escueto y no dilatado, Granada propició la descripción detallada y pormenorizada de los asuntos. Esta diferencia se debe a que el jesuita sostuvo su teoría con la ayuda de la memoria y los dispositivos sensoriales, mientras que Granada se valía únicamente del potencial transformador del propio lenguaje y su capacidad para producir un efecto en el mundo material.

La teoría sobre la descriptio de Luis de Granada se inscribe en un contexto religioso que le asignó un papel fundamental al uso de la imagen como herramienta para la persuasión y control de los fieles. Esta no solo se refiere a las imágenes pictóricas y materiales, sino también a las que se producen "con los ojos internos" y que llamaron mentales. En este contexto, la descripción es la propuesta retórica granatense para aprovechar el valor persuasivo de las imágenes en el plano discursivo. Para el autor, no existen medios únicamente visuales, sino que todo medio de comunicación es multisensorial. Por lo tanto, en la teoría de Granada la importancia radicaría, más bien, en el poder de la descripción como técnica para hacer presente lo ausente, permitiendo que los receptores del mensaje puedan considerar sus pecados y hacer sus vidas más virtuosas y cristianas. De este modo, podríamos pensar que, para el contexto estudiado, la separación entre palabra e imagen es menos productiva en términos analíticos que la que existe entre narración y descripción, como dos técnicas comunicativas que podían ser utilizadas tanto en el plano discursivo como pictórico. 


\section{BIBLIOGRAFÍA}

Abellán, José Luis. Historia crítica del pensamiento español. La edad de oro, volumen 2. Madrid: Espasa Calpe, 1979.

Alonso del Campo, Urbano. Vida y obra de fray Luis de Granada. Salamanca: Editorial San Esteban, 2005.

Álvarez, Marisa. Ut pictura poesis: hacia una investigación de Cervantes, Don Quijote y los emblemas. Washington D. C.: Georgetown University, 1988.

Andrés Martín, Melquiades. Historia de la mística de la Edad de Oro en España y América. Madrid: Biblioteca de Autores Cristianos, 1994.

Arcos Pereira, Trinidad y María Dolores García de Paso. "La traducción al latín de algunos términos y su repercusión en los comentarios a los Aphthonii Progymnasmata". Cuadernos de Filología Clásica. Estudios Latinos, 35.2 (2015): 319-336.

Aristóteles. Poética. Ed. y trad. Valentín García Yebra. Madrid: Gredos, 1974.

Retórica. Ed. y trad. Quintin Racionero. Madrid: Gredos, 1999.

Ávila, Juan de. Obras del venerable maestro Juan de Ávila, clérigo, apóstol de la Andalucía, tomo 2. Madrid: Imprenta Real, 1792.

Barasch, Moshe. The Language of Arts: Studies in Interpretation. Nueva York: New York University Press, 1997.

Bataillon, Marcel. Erasmo y España: estudios sobre la historia espiritual del siglo XVI. $2^{\mathrm{a}}$ ed. México: Fondo De Cultura Económica, 1966.

Bartra, Roger. Cultura y melancolía: las enfermedades del alma en la España del Siglo de Oro. Madrid: Anagrama, 2001.

Bergmann, Emilie. Art Inscribed: Essays on Ekphrasis in Spanish Golden Age Poetry. Cambridge: Harvard University Press, 1979.

Bleichmar, Daniela. "The Imperial Visual Archive: Images, Evidence, and Knowledge in the Early Modern Hispanic World”. Colonial Latin American Review 24.2 (2015): 236-66.

Borriello, Luisi. "Fra Luigi di Granada e Santa Teresa d'Avila". Fray Luis de Granada. Su obra y su tiempo, volumen 1. Actas del Congreso Internacional, Granada, 1988. Eds. Antonio García del Moral y Urbano Alonso del Campo. Granada: Universidad de Granada, 1993. 157-172.

Bray, Xavier. "Lo sagrado hecho real. Pintura y escultura española, 1600-1700". Lo sagrado hecho real. Pintura y escultura española, 1600-1700. Coord. Xavier Bray. Madrid: Ministerio de Cultura, 2010. 15-43.

Brendecke, Arndt. Imperio e información. Funciones del saber en el dominio colonial español. Madrid/Francfort: Iberoamericana/Vervuert, 2012.

Carrillo Castillo, Jesús María. "The Eyes of the New Pliny: The Use of Images in Gonzalo Fernández de Oviedo's Historia general y natural de las Indias". The Art of Natural History: Illustrated Treatises and Botanical Paintings, 1400-1850. Eds. Therese O'Malley y Amy R. W. Meyers. Washington: National Gallery of Art, 2008. 108-25.

Cilveti, Ángel. Introducción a la mística española. Madrid: Cátedra, 1974. 
Christian, William. "Llanto religioso provocado en España en la Edad Moderna". Accidentes del alma. Las emociones en la Edad Moderna. Eds. María Tausiet y James S. Amelang. Madrid: Abada, 2009. 143-66.

Religiosidad local en la España de Felipe II. Trads. Javier Calzada y José Luis Gil Aristu. Madrid: Nerea, 1991.

Corbacho Cortés, Carolina. Literatura y arte: el tópico "Ut pictura poesis". Cáceres: Universidad de Extremadura, 1998.

Cuevas García, Cristóbal. "Santa Teresa, San Juan de la Cruz y la literatura espiritual”. Historia y crítica de la literatura española, vol. 2, tomo 2. Coord. Francisco Rico. Ed. Francisco López Estrada. Barcelona: Crítica, 1979. 238-43.

Delumeau, Jean. El catolicismo de Lutero a Voltaire. Trad. Miguel Candel. Barcelona: Labor, 1973.

De Certeau, Michel. La fábula mística, siglos XVI y XVII. Trad. Jorge López Moctezuma. México: Universidad Iberoamericana, 1993.

Elorriaga del Hierro, Casilda. La descriptio en las retóricas españolas de 1500 a 1565: bases para su estudio, Tesis doctoral. Madrid. Universidad Complutense de Madrid, 1991.

Fabre, Pierre-Antoine. Ignace de Loyola. Le lieu de l'image. Le problème de la composition de lieu dans les pratiques spirituelles et artistiques jésuistes de la seconde moitié du XVI siècle. París: Editions de l'Ecole des Hautes Etudes en Sciences sociales et Librairie Vrin, 1992.

Febvre, Lucien y Henri-Jean Martin. La aparición del libro. Trad. Agustín Millares Carlo. México: Fondo de Cultura Económica, 2005.

García García, Rafael. "El éxito literario de las primeras obras de fray Luis de Granada a la luz de la retórica". eHumanista 24 (2013): 607-27.

Gèlis, Jacques. "El cuerpo, la iglesia y lo sagrado". Historia del cuerpo. Del Renacimiento a la Ilustración. Vol. 1. Dirs. Alain Corbin, Jean-Jacques Courtine y Georges Vigarello. Coord. Georges Vigarello. Trads. Núria Petit y Mónica Rubio. Madrid: Taurus, 2005. 27-111.

González García, Juan Luis. "Retórica del decoro y censura de las imágenes en el barroco temprano español”. Rhetorica: A Journal of the History of Rhetoric 32.1 (2014): 47-61.

Imágenes sagradas y predicación visual en el siglo de oro. Madrid: Akal, 2015.

González Sánchez, Carlos. "Lection espiritual: lectores y lectura en los libros ascético-espirituales de la contrarreforma". Grafías del imaginario. Representaciones culturales en España y América (siglos XVI - XVIII). Eds. Carlos González y Enriqueta Vila Vilar. México: Fondo de Cultura Económica, 2003. 272-300.

Los mundos del libro. Medios de difusión de la cultura occidental en las indias de los siglos XVI y XVIII. España: Universidad de Sevilla, 2001.

Granada, Luis de. Los seis libros de la Retórica Eclesiástica, o método de predicar. 1576. Ed. y trad. Manuel López-Muñoz. Calahorra: Instituto de Estudios Riojanos, 2010.

Libro de la Oración y Meditación en el qual se trata de la consideración de los principales mysterios de nuestra Fe, con oras cosas provechosas. Y de las partes y doctrina para la oración. 1554. Amberes: Viuda de Martín Nucio, 1559.

"De la oración y consideración". Obras del v. p. m. fray Luis de Granada: De la oración y consideración, Memorial de la vida cristiana. Adiciones al Memorial de la 
vida cristiana. Con un prólogo y la vida del autor, por don José Joaquín de Mora, tomo 2. Madrid: Manuel Rivadeneyra, 1860.

Heffernan, James A. W. Museum of Words. The Poetics of Ekphrasis from Homer to Ashbery. Chicago/Londres: The University of Chicago Press, 1993.

Herrero Salgado, Félix. "La Rhetorica Ecclesiastica de fray Luis de Granada y las retóricas cristianas del Siglo de Oro". Fray Luis de Granada. Su obra y su tiempo, volumen 1. Actas del Congreso Internacional, Granada, 1988. Eds. Antonio García del Moral y Urbano Alonso del Campo. Granada: Universidad de Granada, 1993. 265-302.

Huerga, Álvaro. Fray Luis de Granada. Una vida al servicio de la Iglesia. Madrid: Biblioteca de Autores Cristianos, 1988.

Jay, Martin. Ojos abatidos. La denigración de la visión en el pensamiento francés del siglo XX. Trad. Francisco López Martín. Madrid: Akal, 2007.

Kantorowicz, Ernst. Los dos cuerpos del rey. Un estudio de teología politica medieval. Trads. Susana Aikin Araluce y Rafael Blázquez Godoy. Madrid: Akal, 2012.

Kristeva, Julia. "La pasión según Teresa de Ávila". Quaderns de la mediterrània 12 (2009): 184-87.

Ledda, Giuseppina. "Predicar a los ojos". Edad de Oro 8 (1989): 129-42.

Leonard, Irving. Los libros del conquistador. 1953. Trad. Mario Monteforte Toledo, Gonzalo Celorio Morayta y Martí Soler. $2^{\text {a }}$ ed. España: Fondo de Cultura Económica de España, 2006.

López Fe, Carlos María. "El lenguaje afectivo en las "Meditaciones de la Pasión”, de fray Luis de Granada". Fray Luis de Granada. Su obra y su tiempo, volumen 1. Actas del Congreso Internacional, Granada, 1988. Eds. Antonio García del Moral y Urbano Alonso del Campo. Granada: Universidad de Granada, 1993. 207-230.

López Grigera, Luisa. La retórica en la España del Siglo de Oro. Salamanca: Universidad de Salamanca, 1994.

López-Muñoz, Manuel. Fray Luis de Granada y la retórica. Almería: Universidad de Almería, 2000.

"Un episodio en la historia de la comunicación: la Ecclesiastica Rhetorica, de fray Luis de Granada". Luis de Granada. Los seis libros de la Retórica Eclesiástica, o método de predicar. Ed. y trad. Manuel López-Muñoz. Calahorra: Instituto de Estudios Riojanos, 2010. 11-60.

Loyola, Ignacio de. Ejercicios espirituales. 1548. Madrid: Imprenta de D. M. de Burgos, 1833.

Maravall, José Antonio. La cultura del barroco. Barcelona: Ariel, 1975.

Mitchell, W. J. T. "No existen medios visuales". Estudios visuales. La epistemología de la visualidad en la Era de la Globalización. Ed. José Luis Brea. Madrid: Akal, 2005.

Teoría de la imagen. Trad. Yaiza Hernández Velázquez. Madrid: AKAL, Estudios Visuales. 2009.

Osorio, Alejandra. "La entrada del virrey y el ejercicio del poder en la Lima del siglo XviI". Historia Mexicana 55.3 (2006): 767-831.

Pérez Custodio, Violeta. “Introducción”. Ejercicios de Retórica. Introducción, edición crítica traducción anotada e índice a cargo de Violeta Pérez Custodio. Alcañiz/Madrid: Ediciones del Laberinto, 2003. 
Pérez García, Rafael. La imprenta y la literatura espiritual castellana en la España del Renacimiento. Gijón: Editorial Trea, 2006.

Pimentel, Luz Aurora. "Écfrasis y lecturas iconotextuales". Poligrafías 4 (2003): 205-215.

Plett, Heinrich. Enargeia in Classical Antiquity and the Early Modern Age. The Aesthetics of Evidence. Leiden/Boston: Brill, 2012.

Quintiliano. Instituciones oratorias. Eds. y trads. Ignacio Rodríguez y Pedro Sandier. Madrid: Librería de la Viuda de Hernando y Cía., 1887.

Rico Seco, Antonio. "Una gran batalla en torno a la mística: Melchor Cano contra fray Luis de Granada”. Revista de Espiritualidad 34 (1975): 408-427.

Rodríguez Posada, Adolfo. "La pintura verbal: aproximación a los conceptos de descripción, hipotiposis y écfrasis desde la retórica y la teoría literaria". Crossing Boundaries in Culture and Communication 5.2 (2014): 121-131.

Rodríguez de la Flor, Fernando. "La literatura espiritual del Siglo de Oro y la organización retórica de la memoria". Revista de Literatura 90 (1983): 39-85.

Salazar, Verónica. "El cuerpo del rey: poder y legitimación en la monarquía hispánica". Fronteras de la Historia 22.2 (2017): 140-68.

Sánchez Mesa, Martín. "Literatura y plástica en fray Luis de Granada". Fray Luis de Granada. Su obra y su tiempo, volumen 1. Actas del Congreso Internacional, Granada, 1988. Eds. Antonio García del Moral y Urbano Alonso del Campo. Granada: Universidad de Granada, 1993. 135-146.

Spitzer, Leo. Essays on English and American Literature. Princeton: Princeton University Press, 1962.

Stoichita, Víctor. El ojo místico: pintura y visión religiosa en el Siglo de Oro español. Trad. Ana María Coderch. Madrid: Alianza, 1996.

Summers, David. The Judgment of Sense: Renaissance Naturalism and the Rise of Aesthetics. Cambridge: Cambridge University Press, 1987.

Tejada y Ramiro, Juan. Colección de cánones y todos los concilios de la Iglesia de España y de América (en latín y castellano) con notas e ilustraciones, tomo 4. Madrid: Imprenta de Pedro Montero, 1859.

Turrado, Agustín. "El estilo literario de fray Luis de Granada". Fray Luis de Granada. Su obra y su tiempo, volumen 1. Actas del Congreso Internacional, Granada, 1988. Eds. Antonio García del Moral y Urbano Alonso del Campo. Granada: Universidad de Granada, 1993. 159-166.

Velandia Onofre, Darío. "Word and Image in Saint Ignatius of Loyola: The Shaping of Visual Culture in Spanish after the Council of Trent". Word and Image 34 (2008): 332-348.

Hacia una teología de la imagen. Mística, oratoria y pintura en la España del Siglo de Oro. Tesis doctoral. Barcelona: Universitat de Barcelona, 2014.

Webb, Ruth. Ekphrasis, Imagination and Persuasion in Ancient Rhetorical Theory and Practice. Ashgate: Farnham/Burlington, 2009. 